\title{
Food consumption and nutrient intakes with a special focus on milk product consumption in early pubertal girls in Central Finland
}

\author{
A Lyytikäinen ${ }^{1, *}$, C Lamberg-Allardt ${ }^{2}$, L Kannas $^{1}$ and S Cheng ${ }^{1}$ \\ 'Department of Health Sciences, University of Jyväskylä, PO Box 35 (LL), FIN-40014 University of Jyväskylä, \\ Finland: ${ }^{2}$ Department of Applied Chemistry and Microbiology, University of Helsinki, Finland
}

Submitted 6 July 2004: Accepted 17 November 2004

\begin{abstract}
Objective: To evaluate the current status of dietary intakes in early pubertal girls with a special focus on milk products.

Design: Cross-sectional data using 3-day food records.

Subjects: Eight hundred and sixty girls, aged 10-12 years, at Tanner maturation stage I-III.

Results: The mean consumption of milk products $\left(620 \mathrm{~g} \mathrm{day}^{-1}\right)$ was similar to that of a Finnish study in the 1980s, while the consumption of non-milk drinks ( $403 \mathrm{~g} \mathrm{day}^{-1}$ ) had increased. Twelve per cent of the girls had a dairy-restricted diet and consumed significantly less milk products than girls with a non-restricted diet (465 vs. $\left.644 \mathrm{~g} \mathrm{day}^{-1}, P<0.001\right)$. Girls with low milk product consumption had the highest non-milk drinks consumption $(P<0.001)$. The mean energy intake was $7.1 \mathrm{MJ}^{\text {day }}{ }^{-1}$. No major changes were found in the sources of nutrients. The shares of energy for nutrients were close to recommendations except for saturated fat (13.9 vs. $10 \%$ of energy) and carbohydrates ( 51.5 vs. 55-60\% of energy). The mean calcium intake $\left(1117 \mathrm{mgday}^{-1}\right)$ was above the recommendation, while the vitamin D intake $\left(3.1 \mu \mathrm{g} \mathrm{day}^{-1}\right)$ of $88 \%$ of the girls was below the recommendation.

Conclusions: The diet quality of early pubertal girls is close to the recommendations and has improved with respect to fat compared with the 1980s. Consumption of milk products is high although the consumption of non-milk drinks has increased. We found a subgroup of girls who compensate their low milk product consumption with a higher consumption of non-milk drinks. Following a dairy-restricted diet is the main reason for low consumption of milk products.
\end{abstract}

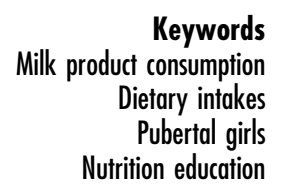

Childhood is a time when basic healthy eating habits can be established. The maintenance of healthy eating patterns and an adequate diet is important during puberty. The diet of children and adolescents has changed during past decades in Finland, like in other Western countries $^{1-3}$. The latest studies on dietary habits of adolescents in Finland indicate that only 13\% of pupils eat their entire school meal although they are served a wellplanned, varied meal (e.g. warm dish, salad, bread and milk), which is even free of charge. Over $60 \%$ of teenage girls drink water instead of milk at school ${ }^{4}$. The consumption of different kinds of snacks, especially soft drinks and candy, during the school day has increased and there is a decreasing trend for having dinner with the family on school days ${ }^{5,6}$. These findings cause concern among nutrition educators.

Earlier studies on Finnish children mostly focused on the prevention of heart disease and specifically on the quality of fat in the $\operatorname{diet}^{7-9}$. The present study is a part of Calex (calcium and exercise) study which aims to prevent osteoporosis. Therefore we focused on the consumption of milk products and intakes of calcium and vitamin D with the purposes of (1) evaluating the current food consumption, nutrient intakes and sources of nutrients in prepubertal and early pubertal Finnish girls and (2) comparing the results with common Nordic nutrition recommendations and earlier Finnish studies for the same age group.

\section{Materials and methods}

\section{Study design}

The subjects were 10-12-year-old volunteers who took part in the screening phase of a large intervention study during autumn 1999 and 2000 to evaluate the effect of calcium and vitamin D supplementation on bone growth. First we contacted class teachers teaching 4 th to 6 th grades in 61 schools in the city of Jyväskylä and the surrounding area in Central Finland (96\% of schools). The teachers asked pupils voluntarily to take home an informed consent form and instructions for both the parents and children on how to fill in the questionnaires and food 
records. Of the 1854 girls who took the materials home, 1163 (63\%) co-signed the informed consent with their parents and agreed to participate in the study. The study protocol was approved by the ethical committees of the University of Jyväskylä, the Hospital of Central Finland and the Finnish National Agency of Medicines.

\section{Subjects}

Of the 1163 girls who agreed to participate in the study, 1043 filled in the screening identification forms and food records. Among them, 80 girls did not have Tanner stage information or the stage was $>$ III (four girls), 10 girls were under ( $<10$ years) or over ( $\geq 13$ years) the target age, and 89 girls did not have either weight or height information or had incomplete food records. Thus the final dataset in this report includes 860 girls $(n=479$ in the year 1999, and $n=381$ in the year 2000).

\section{Anthropometric measurements}

Girls underwent a physical examination conducted by a public health nurse. The physical maturation status was determined by the developmental patterns of the breasts and pubic hair according to the Tanner grading system. If there was a disagreement between the breast and pubic hair development, the final decision was made based on the breast development.

Weight and height were self-reported in 1999, and measured in 2000 with the subjects wearing school clothing and no shoes, and $1 \mathrm{~kg}$ was deducted from the weight for clothes. The self-reported versus measured weight differed significantly only in the girls at age 10 (34.7 vs. $36.0 \mathrm{~kg}, P=0.049$ ) and no differences were found in height.

\section{Food records}

Three consecutive days' food records were completed by the children with their parents' help (two weekdays and one weekend day or in reversed order). The food records contained time of eating, items and portion of food. The families were given written instructions and an example of how to record food consumption with help of a portion guidebook. Details of all foods and drinks, including the type and commercial brand name, were entered in the records. In addition, the type of diet (if restricted) was asked as a separate question. During the coding process, nutrition students checked the food records.

\section{Analysis of nutrient intakes}

Dietary intakes were analysed using the Micro-Nutrica software (version 2.5) developed and maintained by the Social Insurance Institution of Finland. Daily food consumption as foodstuff ingredients was calculated for the following main food groups: cereals, vegetables (including potatoes), fruits (including berries and whole fruit juices), milk products (including cheese), meat, fish, eggs, fats (including butter, margarines and oil), non-milk drinks (including cola drinks, other soft drinks, ready-todrink juices, coffee and tea) and sweets (including sugar, candy and chocolate). We updated the original MicroNutrica database with foodstuffs that had been fortified with calcium (e.g. juices).

For this report, we chose energy and 18 nutrients that we considered indicators for the quality of diet or important nutrients for bone health. Nutrient losses caused by food processing were not taken into account and the intakes of nutrients from supplements were not included. We compared the nutrient intakes with national nutrition recommendations based on the common Nordic Nutrition Recommendations ${ }^{10,11}$.

\section{Statistical analyses}

SPSS version 11.0 for Windows (SPSS Inc., Chicago, IL, USA) was used. All data were checked for normality using the Kolmogorov-Smirnov test. Descriptive statistics are used to present the anthropometric and nutrient data. The independent samples $t$-test was used to compare differences between two groups. One-way analysis of variance followed by the Bonferroni post hoc test was used to compare differences between the quartiles of foods consumed. A $P$-value of $<0.05$ was considered significant.

\section{Results}

\section{Anthropometric and dietary characteristics of the study subjects}

Physical characteristics of the subjects in different age groups are given in Table 1 . In this study, $12 \%$ of the children reported following a dairy product-restricted diet (different stages of lactose intolerance, milk allergy and

Table 1 Tanner maturation stage, weight, height and body mass index (BMI) of the study subjects according to age group. Values are mean (standard deviation) unless indicated otherwise

\begin{tabular}{lcccc}
\hline & All girls $(n=860)$ & $\geq 10$ to $<11$ years $(n=470)$ & $\geq 11$ to $<12$ years $(n=241)$ & $\geq 12$ to $<13$ years $(n=149)$ \\
\hline Age (years) & $11.0(0.9)$ & $10.4(0.3)$ & $11.4(0.4)$ & $12.3(0.3)$ \\
Tanner stage & & & & $16 / 87 / 46$ \\
I/II/IIII $(n)$ & $419 / 367 / 74$ & $332 / 137 / 1$ & $71 / 143 / 27$ & $11 / 58 / 31$ \\
I/II/III $(\%)$ & $49 / 43 / 8$ & $71 / 29 / 0$ & $29 / 60 / 11$ & $43.7(8.3)$ \\
Weight $(\mathrm{kg})$ & $38.2(8.3)$ & $35.6(7.4)$ & $39.9(8.1)$ & $153.9(6.4)$ \\
Height $(\mathrm{cm})$ & $145.7(8.3)$ & $141.7(6.6)$ & $148.6(7.2)$ & $18.4(2.9)$ \\
BMI $\left(\mathrm{kg} \mathrm{m}^{-2}\right)$ & $18.1(2.8)$ & $18.0(2.8)$ & $18.0(2.7)$ & $(2)$. \\
\hline
\end{tabular}


aversion to milk). Three per cent reported food allergies and only six girls a vegetarian diet.

\section{Food consumption}

The daily consumptions of foodstuffs by the main food groups are presented in Fig. 1. On average, the girls consumed $464 \mathrm{~g}$ of milk and $27 \mathrm{~g}$ of cheese per day. During the food record period, $12 \%$ of the girls did not drink milk at all. Of the milk consumers, 54\% used 'light milk' (1.5\% fat) and 30\% used fat-free milk. Seven per cent of the girls used lactose-reduced milks, and 3\% used only sour milk. About $60 \%$ of the girls reported consuming

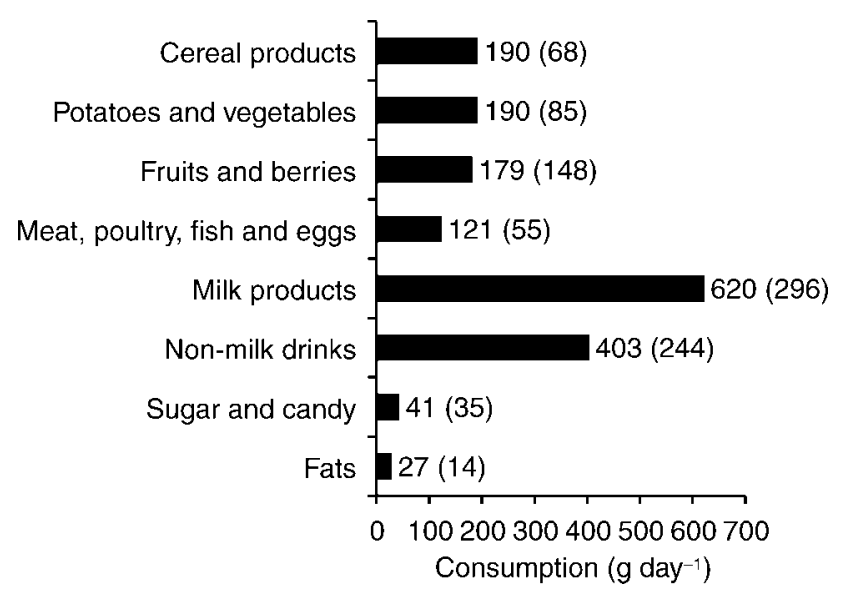

Fig. 1 Mean food consumption by the main food groups (standard deviation in parentheses) different sweetened sour milk products (e.g. yoghurts) and $50 \%$ reported drinking chocolate and eating ice cream at least once during the 3 days.

Girls who reported following a diet restricted for dairy products consumed less milk products than those who had an unrestricted diet (465 vs. $644 \mathrm{~g} \mathrm{day}^{-1}, P<0.001$ ). The average consumption of different kinds of non-milk drinks was $403 \mathrm{~g} \mathrm{day}^{-1}$; the cut-off point for the highest quartile was $543 \mathrm{gday}^{-1}$ and that for the lowest was $219 \mathrm{~g} \mathrm{day}^{-1}$. Soft drinks and ready-to-drink juices were the most popular, and only 30\% of the children drunk coffee or tea. In addition, we found that girls in the lowest quartile of milk products $\left(\leq 404 \mathrm{~g} \mathrm{day}^{-1}\right.$ ) consumed more non-milk drinks ( 490 vs. $352 \mathrm{~g} \mathrm{day}^{-1}, P<0.001$ ) than girls in the highest quartile $\left(\geq 801 \mathrm{~g} \mathrm{day}^{-1}\right)$.

\section{Energy and nutrient intakes}

The mean intakes of energy and nutrients are presented in Tables 2 and 3, and compared with the recommendations. The energy intake distribution was similar to the energy intake reference values of the Finnish recommendations for this age group ${ }^{10}$. Energy intake increased slightly with age from 7.0 to $7.4 \mathrm{MJ}$ day $^{-1}$ (1680 to $1760 \mathrm{kcal} \mathrm{day}^{-1}$, $P=0.075)$. A great majority of the girls (88\%) had vitamin $\mathrm{D}$ intake below the recommended level (milk drinks were not fortified with vitamin $\mathrm{D}$ at the time). The corresponding figures for vitamin $\mathrm{E}$ and folate were $82 \%$ and $73 \%$, respectively. Similarly, over $60 \%$ of the girls had low magnesium and potassium intakes, and 90\% had iron

Table 2 Intakes of energy, energy-yielding nutrients and fibre, and comparison with the Finnish recommendations ${ }^{10}$

\begin{tabular}{|c|c|c|c|c|}
\hline \multirow[b]{2}{*}{ Nutrient and units } & \multirow[b]{2}{*}{ Recommendation } & \multirow[b]{2}{*}{ Mean (SD) } & \multicolumn{2}{|c|}{$95 \%$ confidence interval } \\
\hline & & & Lower & Upper \\
\hline \multicolumn{5}{|l|}{ Energy } \\
\hline MJ & 8.4 & $7.1(1.6)$ & 7.0 & 7.2 \\
\hline kcal & 2010 & $1700(381)$ & 1675 & 1725 \\
\hline \multicolumn{5}{|l|}{ Protein } \\
\hline g & & $66(17)$ & 65 & 67 \\
\hline \% energy & $10-15$ & $15.7(2.7)$ & 15.5 & 15.9 \\
\hline \multicolumn{5}{|l|}{ Fat } \\
\hline g & & $60(19)$ & 59 & 61 \\
\hline$\%$ energy & $\leq 30$ & $31.5(5.6)$ & 31.1 & 31.9 \\
\hline \multicolumn{5}{|l|}{ SFA } \\
\hline \% energy & $<10$ & $13.9(2.9)$ & 13.7 & 14.0 \\
\hline \multicolumn{5}{|l|}{ MUFA } \\
\hline \% energy & $10-15$ & $9.8(2.2)$ & 9.6 & 9.9 \\
\hline \multicolumn{5}{|l|}{ PUFA } \\
\hline \% energy & $5-10$ & $4.5(1.6)$ & 4.4 & 4.6 \\
\hline \multicolumn{5}{|l|}{ Carbohydrates } \\
\hline g & & $218(53)$ & 214 & 222 \\
\hline \% energy & $55-60$ & $51.5(6.1)$ & 51 & 52 \\
\hline \multicolumn{5}{|l|}{ Sucrose } \\
\hline g & & $38(18)$ & 37 & 39 \\
\hline \% energy & $<10$ & $8.9(3.4)$ & 8.6 & 9.1 \\
\hline \multicolumn{5}{|l|}{ Fibre } \\
\hline $\mathrm{g}$ & & $15.2(5.0)$ & 14.9 & 15.5 \\
\hline $\mathrm{gMJ}^{-1}$ & 3 & $2.2(0.7)$ & 2.1 & 2.2 \\
\hline
\end{tabular}

SD - standard deviation; SFA - saturated fatty acids; MUFA - monounsaturated fatty acids; PUFA - polyunsaturated fatty acids. 
Table 3 Intakes of vitamins and minerals, and comparison with the Finnish recommendations ${ }^{10}$

\begin{tabular}{|c|c|c|c|c|c|}
\hline \multirow[b]{2}{*}{ Nutrient and units } & & \multirow[b]{2}{*}{ Recommendation } & \multirow[b]{2}{*}{ Mean (SD) } & \multicolumn{2}{|c|}{$95 \%$ confidence interval } \\
\hline & & & & Lower & Upper \\
\hline Vitamin A & RE & 800 & $942(1411)$ & 848 & 1037 \\
\hline Vitamin D & $\mu \mathrm{g}$ & 5 & 3.1 (1.9) & 3.0 & 3.2 \\
\hline Vitamin E & TE & 8 & $6.1(2.3)$ & 5.9 & 6.2 \\
\hline Thiamin & $\mathrm{mg}$ & 1.0 & $1.1(0.3)$ & 1.1 & 1.1 \\
\hline Riboflavin & $\mathrm{mg}$ & 1.2 & $1.9(0.7)$ & 1.9 & 2.0 \\
\hline Folate & $\mu g$ & 240 & $212(61)$ & 208 & 216 \\
\hline Vitamin C & $\mathrm{mg}$ & 50 & $86(51)$ & 83 & 90 \\
\hline Calcium & $\mathrm{mg}$ & 900 & 1117 (420) & 1089 & 1146 \\
\hline Magnesium & $\mathrm{mg}$ & 280 & $262(64)$ & 258 & 267 \\
\hline Phosphorus & $\mathrm{mg}$ & 700 & $1346(356)$ & 1322 & 1370 \\
\hline Potassium & $\mathrm{mg}$ & 3100 & 2846 (715) & 2798 & 2894 \\
\hline Iron & $\mathrm{mg}$ & $12-18$ & $9.0(2.5)$ & 8.8 & 9.2 \\
\hline Zinc & $\mathrm{mg}$ & 8 & $10.6(3.8)$ & 10.4 & 10.9 \\
\hline
\end{tabular}

SD - standard deviation; RE - retinol equivalents; TE - tocopherol equivalents.

intake below the recommendations. After adjusting for energy, all of these vitamins and iron (mean for vitamin D, $0.4 \mu \mathrm{g} \mathrm{MJ}^{-1}$; vitamin E, 0.9 tocopherol equivalents $\mathrm{MJ}^{-1}$; folate, $30 \mu \mathrm{g} \mathrm{MJ}^{-1}$; iron, $1.3 \mathrm{mg} \mathrm{MJ}^{-1}$ ) remained below the recommended levels.

\section{Sources of nutrients}

The most important sources of energy in the girls' diet were cereals and milk products, both supplying a quarter of the total intake. Milk products yielded $29 \%$ of the total fat intake, while $32 \%$ came from edible fats. The major part of saturated fatty acids (SFA) came from milk products (42\%), whereas margarines and oils were the most important sources of polyunsaturated fatty acids (42\%). Milk products were also the main source of protein (39\%). Cereals supplied about $40 \%$ of the total carbohydrates, but also milk products were a remarkable source of carbohydrates supplying alone $17 \%$ of the total sucrose intake.

Milk and milk products were the most important source of calcium (81\%). Milk products were also a major source of riboflavin, and a remarkable source of magnesium, phosphorus, potassium and zinc $(63 \%, 29 \%, 47 \%, 33 \%$ and $33 \%$, respectively). Vegetables and cereals were equal sources of folate in the diet, both accounting for a quarter of the intake, but milk products yielded nearly as big a share (21\%). Cereals were the main source of fibre (61\%), thiamin (31\%), iron (44\%) and magnesium (31\%). Nearly $80 \%$ of vitamin C intake came from vegetables and fruits. Dietary fats were the major sources of vitamins D and E ( $45 \%$ and 33\%, respectively). Fish alone accounted for $24 \%$ of the vitamin D intake for those girls who ate fish. Half of the girls did not eat fish at all during the food record period.

\section{Discussion}

We found that the most noticeable differences in diet compared with the report of the 1980s were in the consumptions of fats and non-milk drinks ${ }^{7}$. The total consumption of non-milk drinks has nearly doubled. No major differences were found in total consumption of milk products per se and, as a consequence, calcium intake was at the same level as reported earlier. Furthermore, no major changes were found in the sources of nutrients. However, a great many of the children in our study consumed sweetened milk products, which is partly due to their expanded availability over the last 20 years. The total consumption of cereals, as well as of meat, fish and eggs, remained at a similar level as in the early 1980s. Unlike adults, whose consumption of vegetables and fruits has been reported to have increased during the past two decades, girls of the present study consumed a similar amount of vegetables compared with their counterparts in the early 1980s, while fruit consumption decreased slightly $^{7,12}$. Any conclusion about the adequacy of different food groups consumed cannot be stated because of the lack national food-based recommendations.

Energy intake was about $10 \%$ lower in this study compared with reports from the $1980 \mathrm{~s}^{7,13}$. Our finding is in line with some other Finnish studies on the same age group and older children ${ }^{9,14}$. The lower energy intake in this study can be explained by the lower consumption of fat than the levels reported earlier and there has been an overall decrease in the fat content of commonly used foodstuffs (e.g. milk and meat products, bread spreads). We also found a favourable shift in the quality of fat compared with the 1980s, which indicates improved fat quality of the foodstuffs consumed (e.g. bread spreads) ${ }^{7,13}$.

\section{Milk products and the whole diet}

The role of milk products as a source of different nutrients in the diet is similar to that in the earlier report ${ }^{7}$. On the other hand, milk products still yielded a great part of SFA despite their decreased fat content during the past 20 years.

We found in many cases that a modified diet based on intolerance, food allergy or aversion was the reason to 
restrict milk product consumption. Still, the modified diets could not fully explain the reduced dairy product consumption in this subgroup. There is a wide assortment of alternative milk products for lactose-reduced diets in Finland. This indicates that changes in eating habits might be the real reason for reduction of milk product consumption. We also found a subgroup whose low milk product consumption was associated with a high consumption of non-milk drinks. These findings provide a challenge for nutrition educators to design effective ways to reverse the trend towards increasing consumption of soft drinks and different kinds of juices. At the same time, we need to maintain the favourable changes that have occurred in the content and quality of fat in the diet. Promoting the consumption of fat-free milk products and vegetable fats will keep the fatty acid content in balance. Fortification of liquid milk products with vitamin D, which was commenced in the year 2003 in Finland, might increase the intake of vitamin D to the recommended level in milk drinkers. Those children who avoid liquid milk products should be guided to use vitamin D supplements in the dark wintertime.

\section{Metbodological aspects of the study}

Our study has some limitations especially with regard to the non-responders. The children and parents who agreed to participate in this study might be more conscious or concerned about health and nutrition than the nonresponders. In a Swedish study of schoolchildren, the nonparticipants differed significantly from the participants with respect to sociodemographic, lifestyle and dietary factors $^{15}$. In a selected subgroup $(n=258)$ we evaluated the welfare of the children's families by a separate questionnaire. We found the socio-economic status of these families to be similar to that of average Finnish families with children (personal communication). We found that subjects in excluded data were significantly younger, less matured and smaller than the girls in the included data $(P<0.001-0.06)$. This is mainly due to the exclusion criterion of age used. Although the exclusion did not affect the main results, this fact should be taken into account when interpreting our results.

Underreporting is a common cause of bias in dietary surveys using food records and underestimation of energy intake is associated with obesity in adults ${ }^{16,17}$. This may also hold true for children, especially for those who feel that they should be on a diet or are overweight. In our data, especially fat used on bread and added sugar may have been underreported. It is also possible that the low intakes of several nutrients are due to the low total consumption of food. To avoid the biases and possible effects of underreporting, we adjusted the nutrients to energy in our analyses.

In this study all food records were collected near the weekend. This might result in overestimation of the consumption of soft drinks owing to the fact that children drink more soft drinks during the weekend than on weekdays. On the other hand, the method of recording food consumption over three consecutive days can induce a decline in the food items reported over the recording period $^{15}$. However, the 3 -day food record has been evaluated as the best overall choice compared with other dietary methods in the study of 9-10-year-old girls ${ }^{18}$.

\section{Conclusions}

Our results indicate that the most notable differences in food consumption are reduced fat and increased non-milk drink intakes compared with the study conducted in the 1980s in Finland. Milk products turned out to be the main sources of many nutrients. The average milk product consumption is still high and therefore the mean calcium intake is adequate. However, there seems to be a subgroup that compensates their low consumption of milk products with a higher consumption of non-milk drinks. Overall, the mean quality of the diet of the children as evaluated by the shares of nutrients to energy is close to the recommendations, except for saturated fat and carbohydrates. Special focus should be given to those early pubertal girls who have modified diets or restrict their consumption of milk products.

\section{Acknowledgements}

We wish to thank all the children and their parents who participated in the study for making it possible. We would also like to thank Kristiina Ojala, Pia-Leena Salo, Miia Kemikangas and Shumei Cheng, and as well as the rest of the personnel and students, for their assistance in the study. The study was supported by the Academy of Finland, The Finnish Ministry of Education, French Candia Institute, Jyväskylä Science Park, LIKES - Foundation for Sport and Health Sciences, PEURUNKA - Medical Rehabilitation Foundation, Artturi and Ellen Nyyssönen Foundation and Juho Vainio Foundation.

\section{References}

1 Samuelson G. Dietary habits and nutritional status on adolescents over Europe. An overview of current studies in the Nordic countries. European Journal of Clinical Nutrition 2000; 54(Suppl. 1): S21-8.

2 Vereecken C, Maes L. Eating habits, dental care and dieting. In: Currie C, Hurrelmann K, Settertobulte W, Smith R, Todd J, eds. Health and Health Behaviour among Young People. Health Behaviour in School Aged Children: A WHO CrossNational Study (HBSC) International Report. Health Policy for Children and Adolescents (HEPCA) Series No. 1. Geneva: World Health Organization, 2000, 83-96.

3 Nicklas TA, Elkasabany A, Srinivasan SR, Berenson G. Trends in nutrient intake of 10-year-old children over two decades (1973-1994). The Bogalusa Heart Study. American Journal of Epidemiology 2001; 153: 969-77.

4 Urho U-M, Hasunen K. Yläasteen kouluruokailu 2003. Selvitys peruskoulun 7-9 luokkien oppilaiden kouluruokailusta [School Catering in the Upper Level of the Comprehensive 
school in 2003]. Report of Ministry of Social Welfare and Health 2003:17. Helsinki: Ministry of Social Welfare and Health, 2003 [in Finnish with English abstract].

5 Haapalahti M, Mykkänen H, Tikkanen S, Kokkonen J. Meal patterns and food use in 10- to 11-year-old Finnish children. Public Health Nutrition 2003; 6(4): 365-70.

6 National Research and Development Centre for Welfare and Health. The School Health Survey: Food Habits. National Results of the Survey in the Year 2003 [online]. Available at http://www.stakes.fi. Accessed 21 May 2004 [in Finnish]

7 Räsänen L, Ahola M, Kara R, Uhari M. Atherosclerosis precursors in Finnish children and adolescents. VIII. Food consumption and nutrient intakes. Acta Paediatrica Scandinavica 1985; 318(Suppl.): 135-53.

8 Lagström H. Nutrient intake and food choice during a childtargeted coronary heart disease prevention trial. The STRIP Project. Dissertation. Studies in Social Security and Health 41. Turku, Finland: The Social Insurance Institution, 1999.

9 Talvia S, Lagström H, Räsänen $M$, Salminen M, Räsänen L, Salo $\mathrm{P}$, et al. A randomized interventions since infancy to reduce intake of saturated fat: calorie (energy) and nutrient intakes up to the age of 10 years in the Special Turku Coronary Risk Factor Intervention Project. Archives of Pediatrics \& Adolescent Medicine 2004; 158: 41-7.

10 Valtion ravitsemusneuvottelukunta (National Nutrition Council). Komiteamietintö [The Finnish Nutrition Recommendations]. Report of Advisory Committee of Government 1998:7. Helsinki: Ministry of Agriculture and Forestry, 1998 [in Finnish].

11 Nordiska Ministerråd (Nordic Council of Ministers). Nordiska näringsrekommendationer [The Nordic Nutrition Recommendations]. Nord 1996:2. Copenhagen: Nordic Council of Ministers, 1996 [in Swedish].

12 Lahti-Koski M, Kilkkinen AM. Ravitsemuskertomus 2000 [National Nutrition Report]. Publication B1/2001. Helsinki: National Public Health Institute, 2001 [in Finnish with English summary].

13 Räsänen L, Laitinen S, Stirkkinen R, Kimppa S, Viikari J, Uhari M, et al. Composition of the diet of young Finns in 1986. Annals of Medicine 1991; 23: 73-80.

14 Fogelhom M. Diet, physical activity and health in Finnish adolescents in the 1990s. Scandinavian Journal of Nutrition 1998; 42: 10-2.

15 Berg C, Jonsson I, Conner MT, Lissner L. Sources of bias in a dietary survey of children. European Journal of Clinical Nutrition 1998; 52: 663-7.

16 Hirvonen T, Männistö S, Roos E, Pietinen P. Increasing prevalence of underreporting does not necessarily distort dietary surveys. European Journal of Clinical Nutrition 1997; 51: 297-301.

17 Voss S, Kroke A, Klipstein-Grobush K, Boeing H. Is macronutrient composition of dietary intake data affected by underreporting? Results from the EPIC-Potsdam study. European Journal of Clinical Nutrition 1998; 52: 119-26.

18 Crawford PB, Obarzanek E, Morrison J, Sabry ZI. Comparative advantage of 3-day food records over 24-hour recall and 5-day food frequency validated by observation of 9- and 10-year-old girls. Journal of the American Dietetics Association 1994; 94: 626-30. 